Robert James Cerfolio, MD

Cardiothoracic Surgery

University of Alabama at Birmingham 1900 University Blvd

THT 712

Birmingham, AL 35294

doi:10.1016/j.jtcvs.2005.12.063

\section{Extending video-assisted \\ thoracoscopic surgery for trauma: The uniportal approach \\ To the Editor:}

Burack and colleagues ${ }^{1}$ recently demonstrated the versatility of video-assisted thoracoscopic surgery (VATS) in managing complex trauma. Like the authors, we believe that VATS has revolutionized trauma management. In addition to smaller incisions, proponents of VATS now advocate the use of fewer incisions. Did the authors initially evaluate the thoracic cavity using a single port (uniportal approach)? This would have allowed direct visualization of the knife blade, especially during withdrawal, and allowed the lung resection to be undertaken. ${ }^{2}$

We (GR) have been using uniportal VATS successfully for pathology ranging from bullectomy to biopsies for interstitial lung disease. ${ }^{3,4}$ Recently, we extended its role to trauma. A 19-year-old man was admitted with a single gunshot to the right hemithorax. On admission, the patient was hemodynamically stable, in no respiratory distress, and conscious. Examination revealed a $3-\mathrm{cm}$ entry point $4 \mathrm{~cm}$ below the right scapula with no exit site. Chest radiography and computed tomography (CT) revealed a moderate right pneumothorax, with the bullet located in the lower parts of the right hemithorax. A chest drain was inserted through the fourth intercostal space in the anterior axillary line.

The patient was transferred to the operating theatre, where, during single-lung ventilation, the drain was removed, and a 5 -mm $0^{\circ}$ videothoracoscope was inserted through the same incision. The chest cavity, including the entry point, was surveyed to exclude active bleeding. A minimal amount of blood was seen, which was easily suctioned from the costophrenic recess. The diaphragm was retracted with an endoretractor inserted parallel to the videothoracoscope, revealing the bullet in the deepest part of the costophrenic recess, where it was extracted with an Endoclinch (Tyco/Auto Suture; Figure 1). A 32F drain was then placed through the same incision,

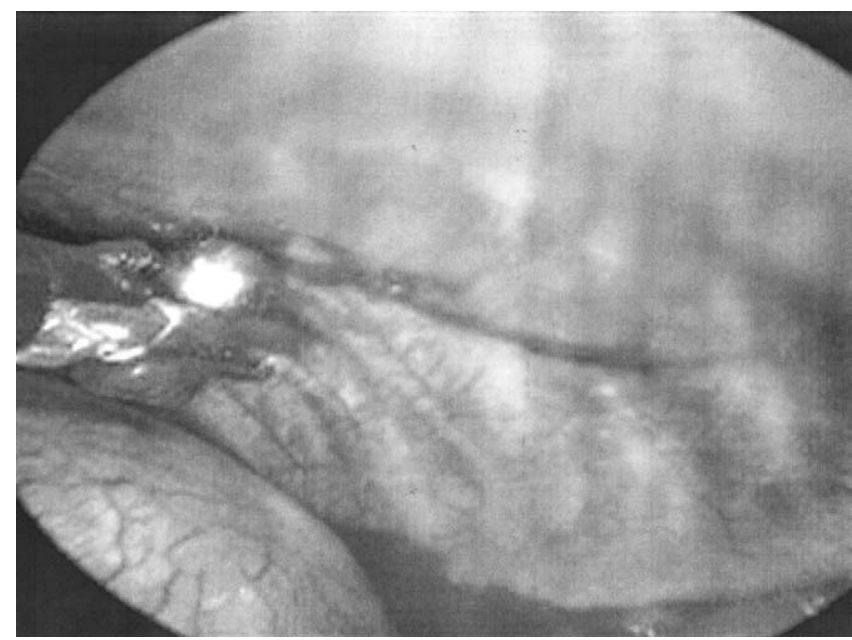

Figure 1. Retrieval of the bullet from the costophrenic recess using the Endoclinch device (Tyco/Auto Suture).

and the patient was transferred to the ward. The drain was removed on the second postoperative day, and the patient was discharged the same evening.

Could the patient have been managed with uniportal surgery, which approaches target lesions in a sagittal plane or from a craniocaudal perspective? The key to preventing interference of instruments is by use of roticulating instruments. These have the unique ability to rotate their stems in addition to moving the jaws independently in all planes and various angles. Perhaps retrospectively the combination of uniportal VATS and high epidural analgesia could have avoided general anesthesia and tracheal intubation in the absence of signs of major pulmonary or vascular involvement? This therapeutic option might represent a potential development of uniportal VATS in the future.

Rajwinder S. Jutley, BMedSci, MRCS, DM Graham Cooper, MD, FRCS (C/Th)

Gaetano Rocco, MD, FRCS(Ed), FECTS

The Price-Thomas Unit of Thoracic Surgery Northern General Hospital

Herries Road S5 7AU

Sheffield, United Kingdom

Dr Rocco is currently affiliated with the Division of Thoracic Surgery, National Cancer Institute, Naples, Italy.

\section{References}

1. Burack JH, Amulraj EA, O’Neill P, Brevetti G, Lowery RC. Thoracoscopic removal of a knife impaled in the chest. $J$ Thorac Cardiovasc Surg. 2005;130:1213-4.

2. Rocco G, Martin-Ucar A, Passera E. Uniportal VATS wedge pulmonary resections. Ann Thorac Surg. 2004;77:726-8.

3. Rocco G, Khalil M, Jutley R. Uniportal videoassisted thoracoscopic surgery wedge lung biopsy in the diagnosis of interstitial lung diseases. J Thorac Cardiovasc Surg. 2005;129: 947-8.

4. Jutley RS, Khalil MW, Rocco G. Uniportal vs. standard three-port VATS technique for spontaneous pneumothorax: comparison of post-operative pain and residual paraesthesia. Eur J Cardiothorac Surg. 2005;28:43-6. doi:10.1016/j.jtcvs.2005.11.051

\section{Reply to the Editor:}

Thank you for the invitation to respond to the letter written by Drs Jutley, Cooper, and Rocco. The worldwide interest in the application of minimally invasive techniques to patients who have sustained penetrating chest trauma is stimulating. The uniportal technique is a novel and innovative approach to thoracoscopic surgery, with the proposed benefit of a single incision and reduced pain. The reported technique requires small roticulated endoscopic instruments, a single incision in the fifth interspace and the posterior axillary line, and an operation performed in a sagittal plane. Furthermore, the reduction of postoperative pain has been documented in a small retrospective series of 16 patients. ${ }^{1}$ However, the interspace is substantially smaller in the posterior rather than anterior thorax, and I suppose that the effect of 